\title{
RAIL-CAR IMPACT TESTS WITH STEEL COIL: CAR CRUSH
}

\author{
Eloy Martinez \\ David Tyrell \\ John Zolock \\ Volpe National Transportation Systems Center \\ US Department of Transportation \\ Cambridge, MA 02142 USA
}

\section{ABSTRACT}

Two grade-crossing impact tests were conducted in June 2002 at the Federal Railroad Administration's (FRA's) Transportation Technology Center in Pueblo, Colorado as part of the FRA's research into passenger equipment crashworthiness. In both of these tests a cab car moving at approximately $14 \mathrm{mph}$ impacted a standing coil of steel supported by a frangible table. The coil was positioned such that the left-side corner post of the cab car sustained the brunt of the impact. The cars were instrumented to measure the accelerations of the carbody, the displacements of the suspensions, the displacements of the corner posts, and the strains in selected structural members. The coil was instrumented to measure its three-dimensional acceleration, including yaw, pitch, and roll. On-board and wayside high-speed film and video cameras were used to record the impact. On June 4, 2002 a cab car compliant with general industry practice circa 1999 was tested and on June 7, 2002 a cab car compliant with current FRA regulations and American Public Transportation Association (APTA) Standards and Recommended Practices for Rail Passenger Equipment was tested.

The tests themselves were conducted in response to a recommendation from the APTA Passenger Rail Equipment Safety Standards (PRESS) Committee to measure the crashworthiness performance of alternative cab car end structures. During the test of the 1990's design, the corner post failed, eliminating the survival space for the operator. During the test of the state-of-the-art design cab car, the corner post remained attached and deformed less than 9 inches, preserving space for the operator.

Prior to the test, crush analyses were conducted to determine the force/crush characteristics of the two end structure designs, as well as their modes of deformation. Collision dynamics analyses were also conducted to determine the extent of crush and the gross motion of the car and coil. This paper describes the analysis of the crush behaviors of the two different end structure designs. A companion paper describes the results of the collision dynamics analyses.

The crush of the cars was analyzed using detailed finite-element models. The impact end of each car was modeled, including approximately $1 / 4$ of the length of the car. The back end of the cab car model was fixed, and its end structure was impacted by an initially moving cylinder with the same mass and dimensions as the steel coil used in the tests.

Prior to the tests, runs were made with the models with and without material failure. This approach allowed calculation of an upper bound and a lower bound on the force/crush characteristics. The pre-test predictions of the analysis of the state-of-the art car including material failure very closely match the results of the test for the force/crush characteristic, strains at the measured locations, the geometry of the deformed structure, and the locations and extent of material failure. The pre-test predictions of the analysis of the 1990's design also closely match the test measurements, however, the extent of material failure predicted was slightly less than observed in the test; failure of the corner post was predicted to occur at a speed of a 1.6 mph (approximately 10\%) greater than the test speed. A more sophisticated implementation of the material failure modeling helped bring the model results into very close agreement with the test measurements.

\section{INTRODUCTION AND BACKGROUND}

The aim of crashworthiness studies is to minimize the possibility of injuries or fatalities caused by the loss of occupant volume, and decelerations and force loads caused by secondary impacts. The results presented in this paper describe the improvement in preserving the cab car operator's survival volume during a grade crossing collision. The scenario envisioned is that of a cab car striking a heavy object in an offset manner where the primary structure involved is the $\mathrm{cab}$ car corner post. A typical design from pre-1999 federal regulations (termed the 1990's design) and a modified design compliant with current federal regulations and APTA's manual of recommended practices (termed the State-Of-the-Art or SOA design) are presented.

The FRA has been supporting APTA's development of its manual of recommended practices [1] with technical information. The FRA, at the request of APTA, has conducted several studies to further the development of APTA's manual. These studies include analysis of the risk of collision in various passenger equipment operating environments, dynamic sled test of passenger seats [2] and dynamic test of glazing response to bullets and thrown objects [3].

Additionally, the FRA has conducted a number of full-scale impact tests. The conditions and the sequence of the tests are listed in Table 1. The first four tests define the crashworthiness of conventional equipment; the second four tests are to measure the performance of improved-crashworthiness equipment. This arrangement allows comparison of the conventional-equipment performance with the performance of crash-energy management equipment in the in-line tests, i.e., the single-car, the two-car, and the train-to-train tests; and the comparison of the performance of a cab car compliant with general industry practice circa 1999 with the performance of a cab car compliant with current regulations and 
standards in the grade-crossing tests, i.e, the single-car impact with a steel coil.

To date, the first three in-line tests for existing-design equipment $[4,5,6]$ and the two grade-crossing tests have been conducted. Testing of improved crashworthiness design equipment, incorporating crushable end structures, in the tests based on the in-line collision scenario is planned to start in the spring of 2003.

Table 1. Planned Sequence of Full-scale Passenger-Equipment Impact Tests

\begin{tabular}{|l|l|l|}
\hline Test Conditions & $\begin{array}{l}\text { Conventional- } \\
\text { Design } \\
\text { Equipment }\end{array}$ & $\begin{array}{l}\text { Improved- } \\
\text { Crashworthiness } \\
\text { Design Equipment }\end{array}$ \\
\hline $\begin{array}{l}\text { Single-car impact with } \\
\text { fixed barrier }\end{array}$ & $\begin{array}{l}\text { November 16, } \\
1999\end{array}$ & Test 6 \\
\hline $\begin{array}{l}\text { Two-coupled-car impact } \\
\text { with fixed barrier }\end{array}$ & April 4, 2000 & Test 7 \\
\hline $\begin{array}{l}\text { Cab car-led train impact } \\
\text { with locomotive-led train }\end{array}$ & January 31, & Test 8 \\
\hline $\begin{array}{l}\text { Single-car impact with a } \\
\text { steel coil }\end{array}$ & June 4, 2002 & June 7, 2002 \\
\hline
\end{tabular}

The grade-crossing tests presented in this paper were conducted in order to evaluate the effectiveness of a corner post compliant with current requirements. Figure 1 is a schematic of the grade-crossing test. This test includes a steel coil supported on a frangible table such that the coil, weighing approximately $40 \mathrm{kips}$, was centered on the corner post in plan view, and that the bottom of the coil was just above the height of the cab car floor. The objective of the test was to measure the effectiveness of the corner post design in preserving the occupant volume. Two different end frame designs were tested: one typical of practice in the 1990's and one compliant with current FRA regulations and APTA recommended practices. In both tests the coil was impacted at approximately $14 \mathrm{mph}$. This speed was chosen so that there would be excessive intrusion (more than 12 inches) into the operator's volume in the test of the 1990's design, and limited intrusion (less than 12 inches) in the test of the SOA design. The test conditions were developed in part based on the Portage, Indiana collision between a cab-car led commuter train and a tractor-tandem trailer carrying coils of steel [7] and the Yardley, Pennsylvania collision between a cab-car-led commuter train a tractor semi-trailer carrying coils of steel [8].

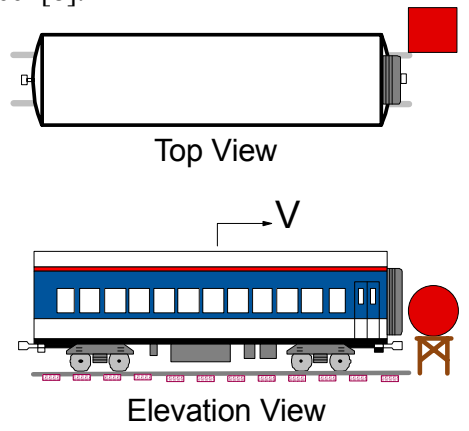

Figure 1. Schematic of In-Line Collision Scenario

The test requirements and the end structure designs were developed in coordination with the Construction/Structural Subcommittee of APTA's Passenger Rail Equipment Safety Standards Committee. An overview of the end structure designs tested is given in the appendix to this paper. A summary of the test requirements is presented in the appendix in a companion paper [9].

\section{SUMMARY RESULTS OF GRADE CROSSING TESTS}

In planning the grade-crossing test, extensive analyses were conducted to determine the impact speed and the measurement requirements; the results of these analyses are described in detail in this paper and in the companion paper [9]. However, the principal results of these tests themselves can be described without reference to the analyses. The results from these analyses allowed for the design of the tests such that the operator's survival space was substantially reduced for the 1990's design cab car and preserved for the SOA design cab car.

Figure 2 shows a photograph of the test setup for the 1990's design. The car was instrumented to measure the accelerations of the carbody, the displacements of the suspensions, the displacements of the corner posts, and the strains in selected structural members. The coil was instrumented to measure its three-dimensional acceleration, including yaw, pitch, and roll. On-board and wayside high-speed film and video cameras were used to record the impact. The same instrumentation setup was used in the test of the SOA design. In both tests, a locomotive was used to push the cab car up to speed; the cab car was then released and impacted the coil.

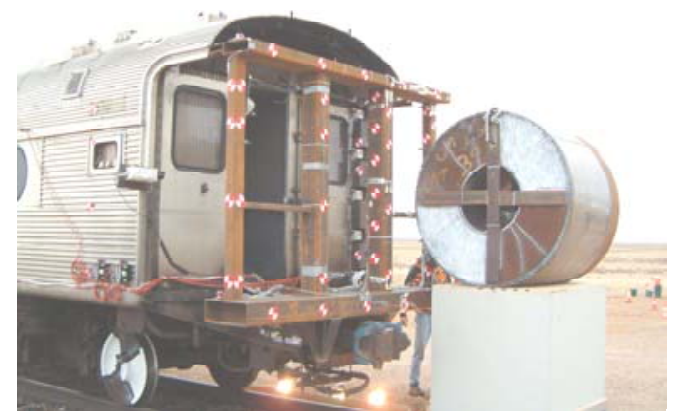

Figure 2. Setup of 1990's design test

Figure 3 shows the final deformed shapes taken from the tests of the 1990's design and the SOA design. During the test of the 1990's design, the corner post pulled out of its attachment at the top. The results of the test show that this corner post design is not sufficient to preserve the operator's volume in such an impact. During the SOA design test, the corner post remained attached. The maximum rearward deformation measured was approximately $81 / 2$ inches. The results of this test show that the SOA design is sufficient to prevent the operator from being crushed in such an impact.

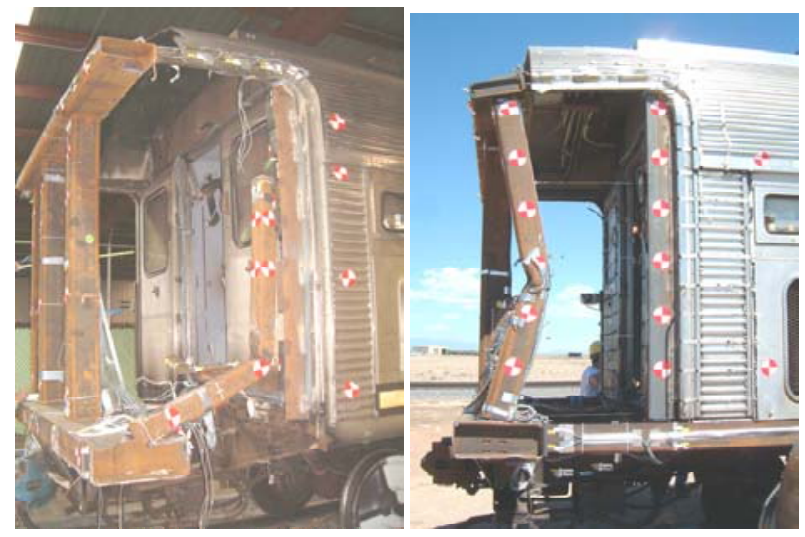

Figure 3. Post-Test Photographs of 1990's and SOA Design Cab Cars 


\section{CAB CAR END STRUCTURE DESIGNS}

Two Budd Pioneer cars [10] were modified with new end structure designs. Figure 4 shows a schematic of the key structural elements of the cab car structure designs. The draft sill, body bolster, and cant rail from the Pioneer car were retained, while the anti-telescoping plate, end beam, collision posts, corner posts and lateral member/shelf were replaced with updated designs. Many of the elements are similar for the 1990's and SOA designs, including the end beams and antitelescoping plates. The principal differences between the two designs are the size of the corner posts, the presence of a bulkhead sheet attached to the lateral member/shelf to the collision post to the corner post and to the end beam on the SOA design, and the length of the side sill on the SOA design which extends past the rear operator compartment to the end beam removing the presence of the step well.

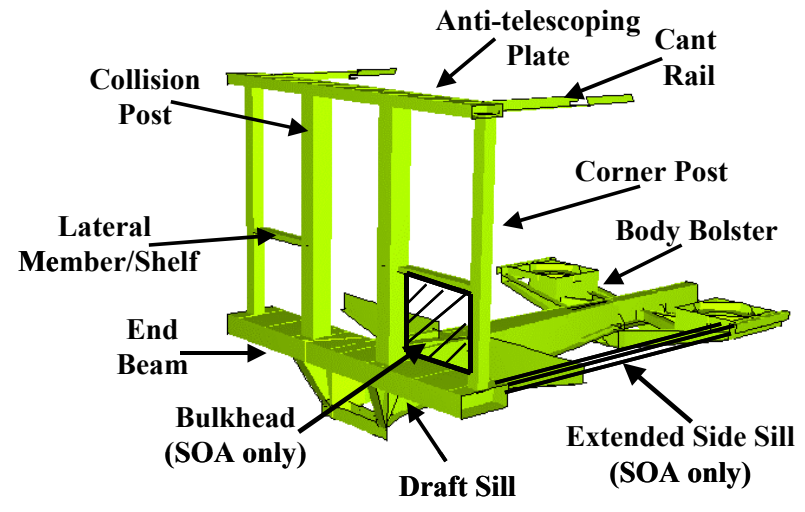

Figure 4. Schematic of Cab Car End Frame Design Features.

Figure 5 shows the difference in size and material thickness for the cross-sections developed for the corner posts in the 1990's and SOA designs. The material from which both designs are constructed is an A710 Grade A Class 3 steel. The 1990's design corner post penetrates and is welded only to the bottom and top plates, respectively, of the anti-telescoping plate and the end beam. In contrast, the SOA design corner post penetrates through both flanges of the end beam and the anti-telescoping plate.

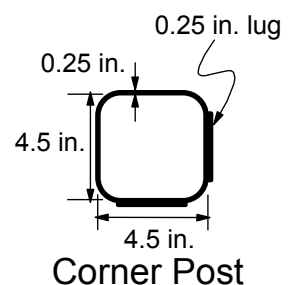

1990's Design

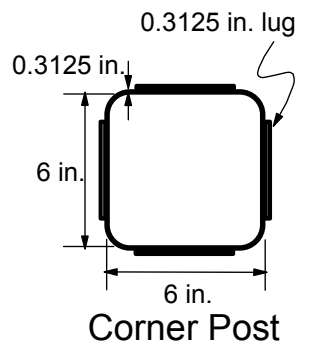

SOA Design
Figure 5. Cross-Sections of Corner Posts from 1990's and SOA Designs

\section{COMPARISON OF ANALYSES AND MEASUREMENTS FOR THE GRADE-CROSSING TESTS}

Prior to the tests, analyses were conducted in order to determine the conditions of the test, including the impact speed, and to determine the quantities to be measured. The tests were analyzed in two steps:
Step 1: Car Crush Behavior. Detailed dynamic, non-linear, large displacement finite-element models of the 1990's and SOA cab car structures were developed. An approximation to the loading condition in the test was used in these models. The principal purpose of these models was to develop the force/crush behaviors and the modes of deformation for the cab car designs. These models have been implemented in ABAQUS/Explicit [11], and all include the influence of material failure.

Step 2: Train Collision Dynamics. Three-dimensional lumped-mass collision dynamics models were used to determine the trajectories of the cab car and coil. Impact elements were used in these collision dynamics models, with the parameters for these elements taken from the results of the finite-element analyses of car crush behavior. The collision dynamics models were used to evaluate the extent of crush as a function of impact speed.

This approach was chosen so that the finite-element models could be constructed to represent the geometries of the cab car structures with great fidelity using highly refined meshes. Accurate and detailed representation of the structure geometry is required to predict the mode of deformation of structure when it collapses [12], and refined meshes are required to avoid artificially increasing the stiffness of the structure [13]. Such models are computationally intensive - requiring several days to execute on an engineering workstation. The approach chosen requires only a few runs to be made with the crush model to develop the desired information, but many runs to be made with the collision dynamics model. As described in the companion paper [9], the collision dynamics lumped-parameter model runs in less than five minutes. This paper describes the finite-element crush models and the predictions made with those models.

\section{Crush Model}

Figure 6 shows the circa 1990 design finite element model of the cab car. Approximately $1 / 4$ the length of the car is modeled. For most of the model, the characteristic element length is about 3 inches. For the corner post and the area around its attachments, the characteristic element length is typically less than $1 / 2$ inch, and in some cases less than $1 / 4$ inch. In the model, the translations of the rear-most elements of the cab car are fixed. The rigid coil is initially given a longitudinal velocity, and is then free to translate and rotate during the simulated impact. In order to bound the range of response, the model was run with and without material failure. The finite element car crush model for the SOA design is similar to the model of the 1990's design.

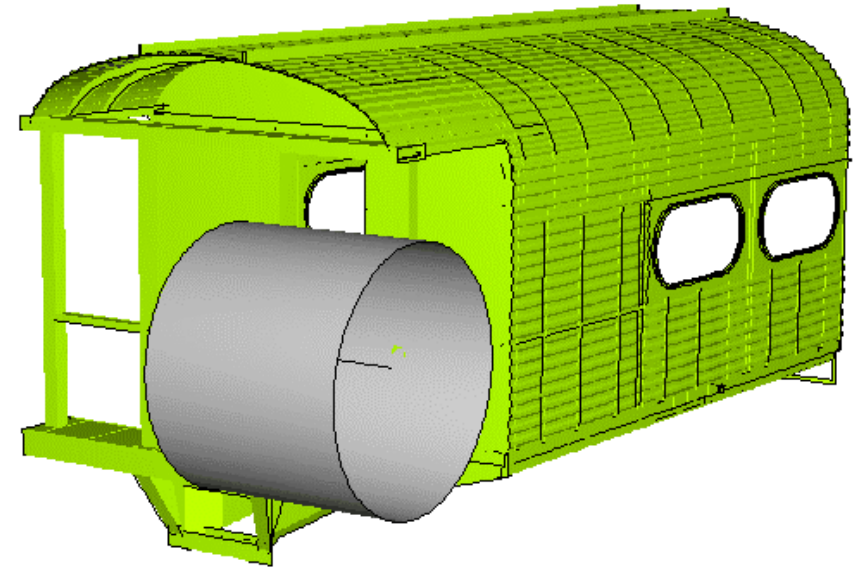

Figure 6. Finite-element Car Crush Model, 1990’s Design 
The following sections provide a detail description of the results predicted prior to conducting the tests in order to develop the instrumentation requirements. Test measurements are contrasted to the pre-test predictions. The 1990 design crush model was modified after the tests were conducted to capture a failure mode not predicted beforehand but observed at the test, and these results are also compared against the test measurements.

\section{Circa 1990's Design}

Figure 7 shows the force/crush characteristic developed for the 1990 's design as predicted with the model and as measured during the test. Both pre-test and post-test predictions are shown on the plot. The pre-test predictions from the analysis including material failure and the test measurements are in close agreement up to approximately 12 inches of crush. After 12 inches of crush, the pre-test predictions show the force increasing, while the test measurements show the force decreasing. A source of the discrepancy could have resulted from late changes in the attachment of the anti-telescoping plate to the cant rail that were not incorporated in the model prior to the test and from limitations of the current approach to modeling material failure in finite-element solvers. As a result, failure of the upper attachment of the corner post occurred sooner in the test than predicted.

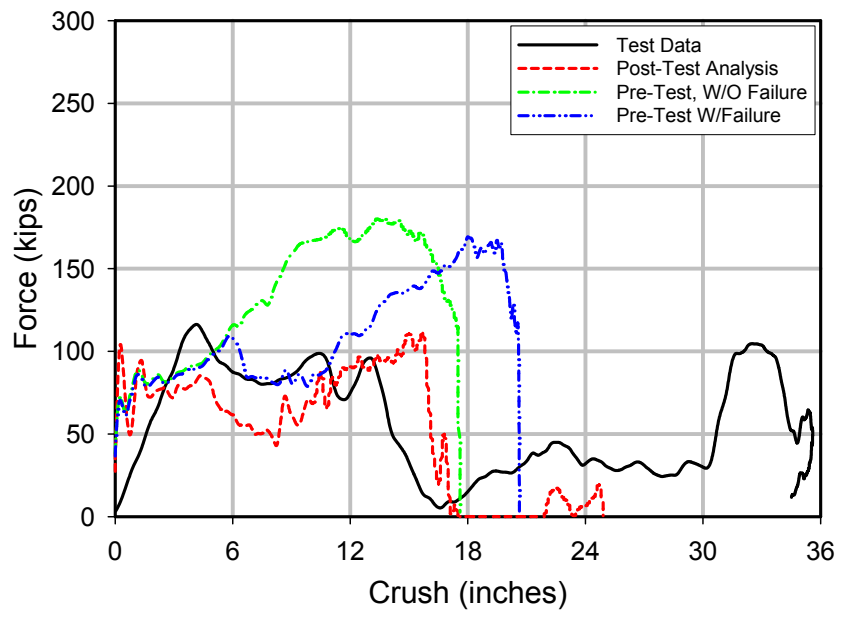

Figure 7. Measured and Predicted Fore/Crush Characteristic, 1990's Design

Instead of attaching the anti-telescoping plate to the cant rails with several short gussets, as initially designed, doublers were used over the cant rails up to the bulkhead wall. In addition, several gussets were used where the doublers met the bulkhead wall. The model was revised after the test to include these changes. These changes increased the stiffness of the anti-telescoping plate support, which in turn increased the stiffness of the upper attachment of the corner post.

Figure 8 shows the force time post-test finite element results as well as the derived force time curve taken from test measurements. A nine-accelerometer array was used on the steel coil for the test and the force presented is the resolved acceleration times the mass of the steel coil. The results from the simulation and those derived from the test are very close for the first 0.03 seconds. Between 0.03 seconds and 0.05 seconds the measurements are showing somewhat elevated force levels compared to the analysis $(\sim 25 \%$.) Again the results overlay one another between 0.05 seconds and 0.06 seconds. The key difference occurs after 0.06 seconds where the measurements indicate softening behavior due to the failure of the lateral member/shelf and pull-out of the corner post from the anti-telescoping plate over $\sim 0.015$ seconds.
The model is predicting a peeling/tearing failure of the lateral member/shelf from the corner post thereby losing a source of load transfer. This resulted in a decreased load in the finite element results between 0.02 seconds and 0.05 seconds. The pull-out failure of the corner post from the anti-telescoping plate occurs in the finite element model around 0.1 seconds. The softening behavior occurs over a much shorter time frame $\sim 0.004$ seconds. The differences in predicted failure response in time is not surprising given the current state-of-the-art in ductile fracture modeling.

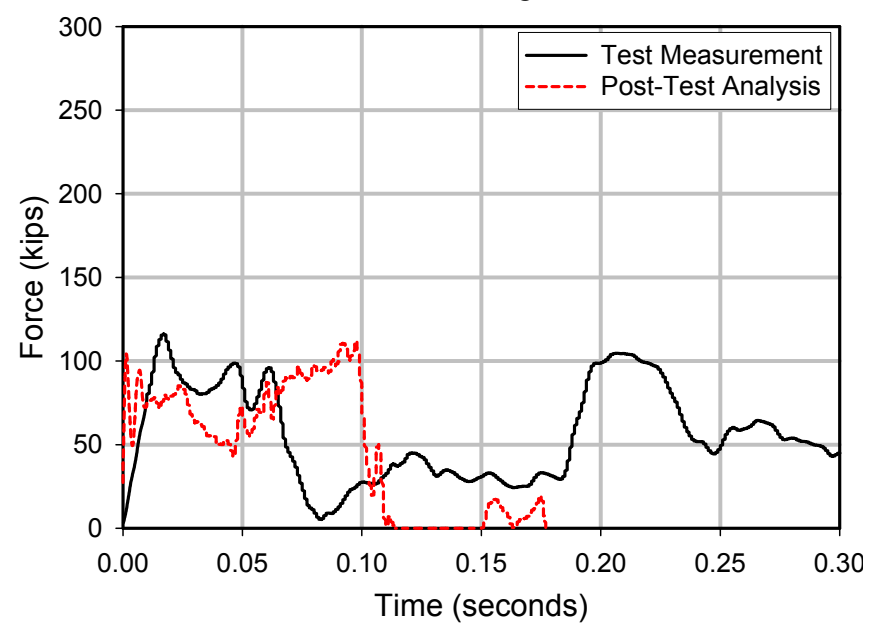

Figure 8. Measured and Predicted Force-Time History, 1990's Design

Currently, material failure is modeled in many finite-element analysis packages using a simple strain-to-failure criterion. When the total strain on an element reaches a prescribed value, that element is removed from the mesh. This approach works well when the principal cause of material failure is tension and the extent of material failure is limited. An additional concern in modeling failure using this approach is the dependence of predicted strain and hence failure with mesh size. The finer the mesh the greater accuracy in capturing higher strain gradients and higher strain levels. The post-test model used a much finer mesh than the original model and the failure criterion was adjusted based upon the stress state and mode of failure. A lower strain-to-failure criterion was used in the area where the corner post pulled out of the anti-telescoping plate. The combination of the finer mesh and lower strain-to-failure criterion coupled with the stiffer connection caused the post-test model to fail in a manner similar to what was observed in the test. There is a small discrepancy in the results; the test measurements show pull-out occurring sooner and lasting longer than what is predicted in the post-test simulation.

Figure 9 shows a comparison of the post-test finite element results taken from corresponding positions on the corner post as the measured longitudinal displacements taken from selected string potentiometers. String potentiometer position varies from bottom to top starting at position 1 and ending at position 5 with the lead letter differentiating the test measurement (T) from the analysis result (A). The string potentiometers are symmetrically placed to equally divide the corner post between the end beam and the anti-telescoping plate.

A detailed discussion of the information presented by TSP3 is given which is representative of the mechanisms occurring for all the string potentiometers. The first slope occurs between initial impact and 0.01 seconds which corresponds to $\sim 2.75$ inches of displacement. The second slope range occurs between 0.01 seconds and 0.09 seconds 
and corresponds to failure of the lateral member/shelf as well as pull down of the anti-telescoping plate. Finally, between 0.07 seconds and 0.09 seconds the last slope corresponds to pull-out of the corner post from the anti-telescoping plate. It is interesting to note that lag time in response from the position of TSP3, TSP4, and TSP5. The nearest string potentiometer to the anti-telescoping plate, TSP5, notices disturbances from the anti-telescoping plate before the further removed string potentiometer, TSP3. The test data has only been plotted to just after failure of the anti-telescoping plate attachment; data past that time is unreliable due to failure of the gauges.

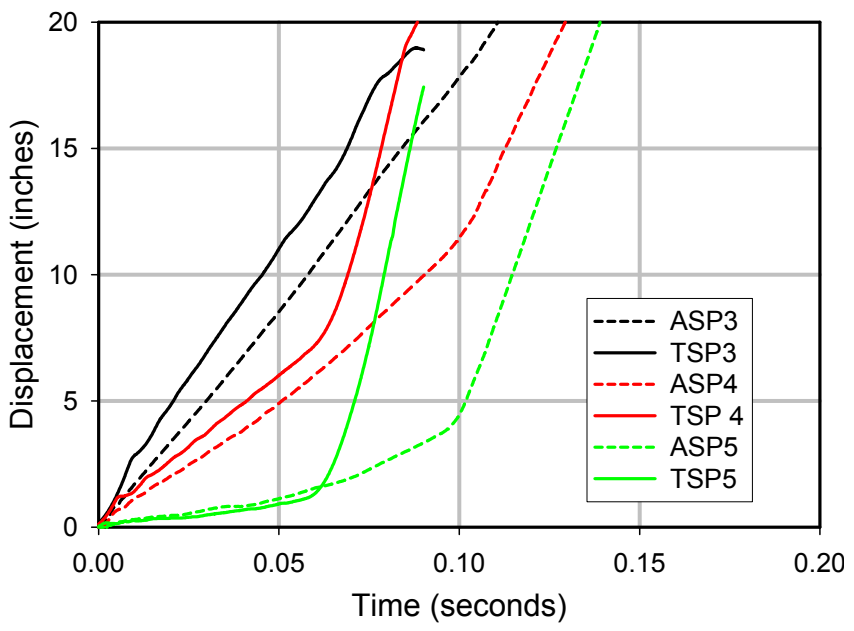

Figure 9. Measured and Predicted Longitudinal DisplacementTime Histories on Circa 1990 Corner Post

The maximum measured displacement of the corner post near the point of impact, prior to separation of the anti-telescoping plate attachment, taken from this figure is approximately 19 inches. Upon pull-out, there is some elastic recovery and post- test measurement showed that the corner post was permanently deformed by 18.5 inches.
Figure 10 shows three still photographs taken from a high-speed movie film of the 1990's design grade-crossing test. The first frame shows the coil and corner post at the instant of impact. The second frame shows the coil and cab car just prior to complete failure by pullout of the corner post from the anti-telescoping plate at $\sim 0.08$ seconds. At this time the post has displaced inwards 18 inches. The third frame shows the coil and cab car after 0.09 seconds and 19 inches of displacement of the corner post. Just below those three frames are results from the pre-test analysis with material failure for the mode shape of the cab car end structure at the same times and nearly the same displacements.

The predicted mode shape matches the mode shape observed in the test but for one detail: in the third frame, the frame from the test shows only a small amount of vertical distortion of the roof above the upper rear corner of the near-side doorway, while the frame from the model predictions shows more distortion of the top of this doorframe. This difference in mode may be due to the changes in the attachment of the end frame to the original car structure as well as the strain-tofailure criterion used. In addition, note the difference in length of roof material not present on the test vehicle. The original model integrally attached roof sheeting to the anti-telescoping plate, which experiences a counter-clockwise torque as the anti-telescoping plate is pulled downwards. To maintain compatible deformations this load is reacted above the doorframe where a plastic hinge is formed in the cant rail, the roof sheeting, and the hat sections on top of the roof.

Despite the minor differences discussed between the pre-test, posttest, and test measurements overall there is very good agreement in terms of total energy consumed through plastic deformations as well as modes of deformation and failure. This information is then provided as input into the collision dynamics models discussed in the companion paper. Further work is currently underway to develop a better engineering failure algorithm that can be incorporated into the finite element solver. The goal of this work is to be able to account for failure in a component by combining not only strain states but also the stress states $[14,15]$.
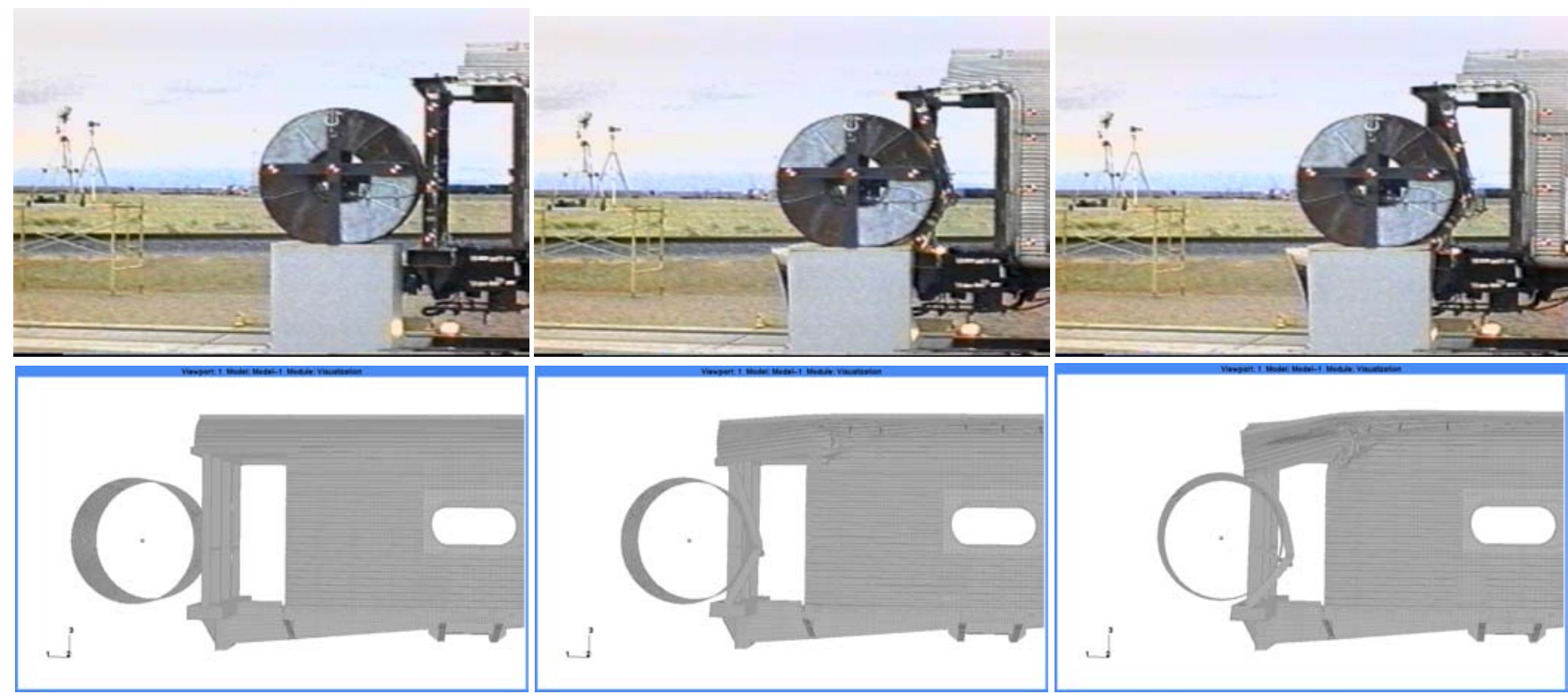

Figure 10. Measured and Pre-Test Predicted Mode of Deformation, 1990's Design, Up to Corner Post Upper Attachment Failure 
Figure 11 shows a still photograph taken from the high-speed film. This frame shows the failed upper attachment of the corner post. Just below the photograph is a plot of the deformed mesh from the revised finite-element analysis. The coil has been removed for clarity. The results of the revised analysis are in close agreement with the test observations. The pull-out mode of failure has been captured using the model with a refined mesh and a lower strain-to-failure criterion in the anti-telescoping plate's material. There is a shift in the time it takes for the pull-out failure to occur as noted in the string potentiometer discussion.
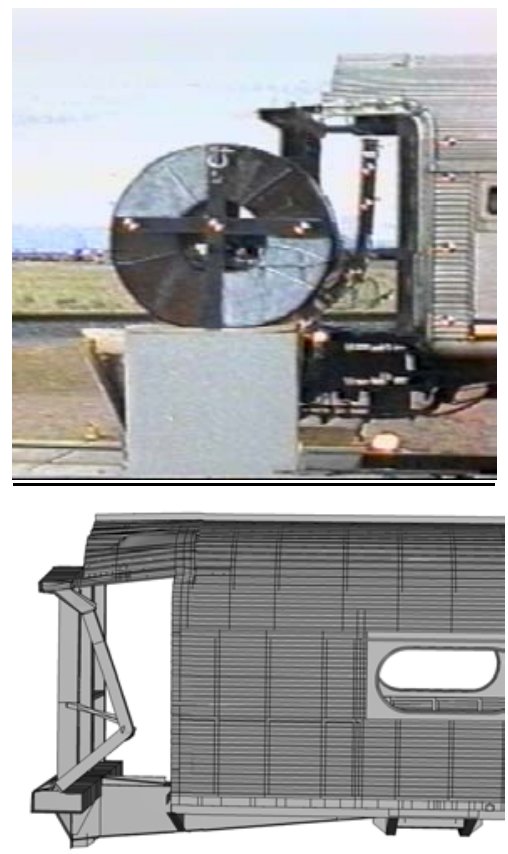

Figure 11. Measured and Post-Test Predicted Mode of Deformation, 1990’s Design, Corner Post Upper Attachment Failure

\section{State-of-the-Art Design}

Figure 12 shows the pre-test predictions for the force/crush characteristic for the State-of-the-Art Design. The model was exercised with and without material failure. The model predictions with material failure nearly overlay the test results. Similar to the results discussed with the circa 1990 design, there is a small phase shift in the timing of events. The peak load caused by the initial contact occurs almost instantaneously for the finite element model and is higher than what occurs in the test measurements. As seen from the test measurements, there is a finite rise time for the initial load and the peak load is smaller. In both the test measurements and the crush model results the initial peak is associated with the formation of the central plastic hinge on the corner post. The second and third peaks with their associated load plateaus correspond to the formation of the plastic hinges at the corner post/end beam connection and the corner post/anti-telescoping plate connection respectively. The difference between the crush models with and without failure is apparent after 4 inches of crush. The model without failure considerably over predicts the load after 6 inches of crush, but has a similar unloading slope as observed in the test. The model with failure predicts slightly higher loads after 7 inches of crush but the same maximum crush distance as observed in the test. However, the rate of unloading predicted with the no failure model is slower than observed in the test.

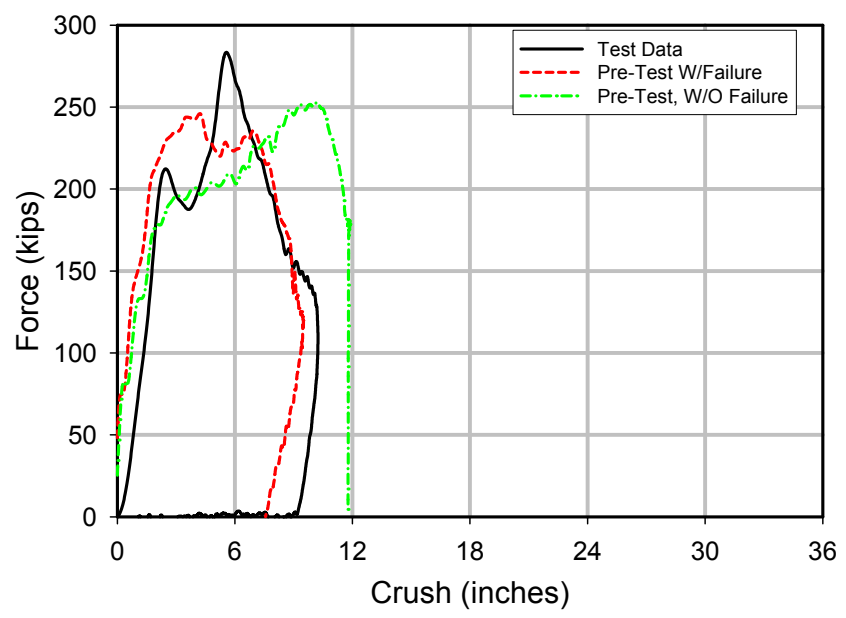

Figure 12. Measured and Predicted Fore/Crush Characteristic, SOA Design

Figure 13 shows the force time comparison of the test measurements and the crush model with failure. The force time trace from the test was derived using the resultant deceleration taken from the nine-accelerometer array on the coil multiplied by the coil mass. The results presented are unfiltered. Despite the minor inconsistencies between the test measurements and the crush model results, there is very good agreement. The phase shift experienced in the model is not surprising given the simplicity of the failure criterion used. As elements fail and are removed and depending on the size of the mesh too much material is removed making the response predicted softer that what occurred in the test.

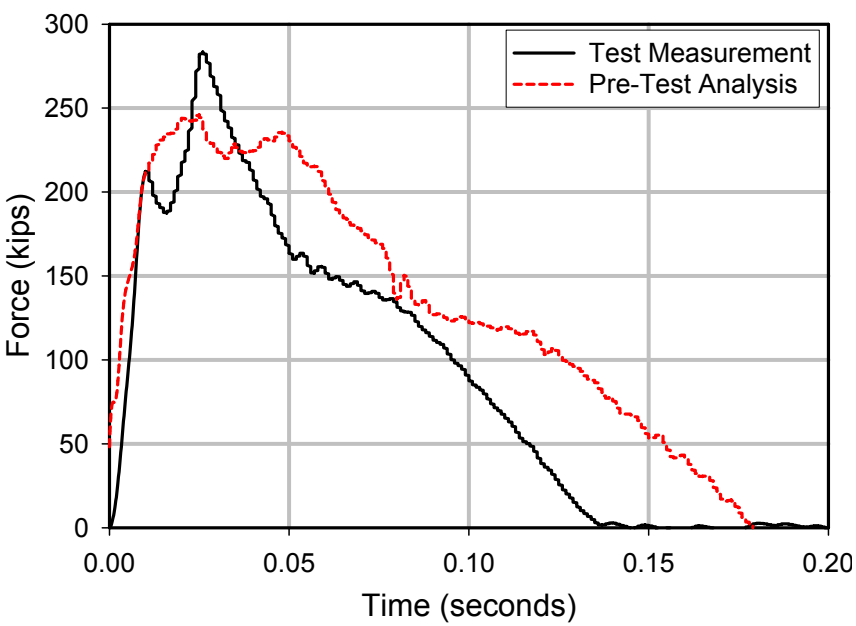

Figure 13. Measured and Predicted Force-Time Histories, SOA Design

Figure 14 shows a comparison of the measured string potentiometer longitudinal displacement (solid line) with that predicted prior to the test (dashed line.) The crush model results reflect the average displacement taken at the centroid of the center element at the appropriate height on the corner post. The results presented are for the same string potentiometers as discussed in the 1990's design discussion above. Initially the displacements predicted in the crush model are less than those measured in the test at a given point in time which means the response predicted is stiffer. However when failure is predicted to start in the model, the structural stiffness 
decreases due to too much material being removed during element removal. While the peak predicted displacements are larger in the model than predicted by the tests the unloaded final displacements are close. The flat lines at the end of each test result plotted show the final position of the post after rebound of the coil has occurred. The test measurement taken at the point closest to the point of initial contact is 8 inches while that predicted by the model is 8.5 inches.

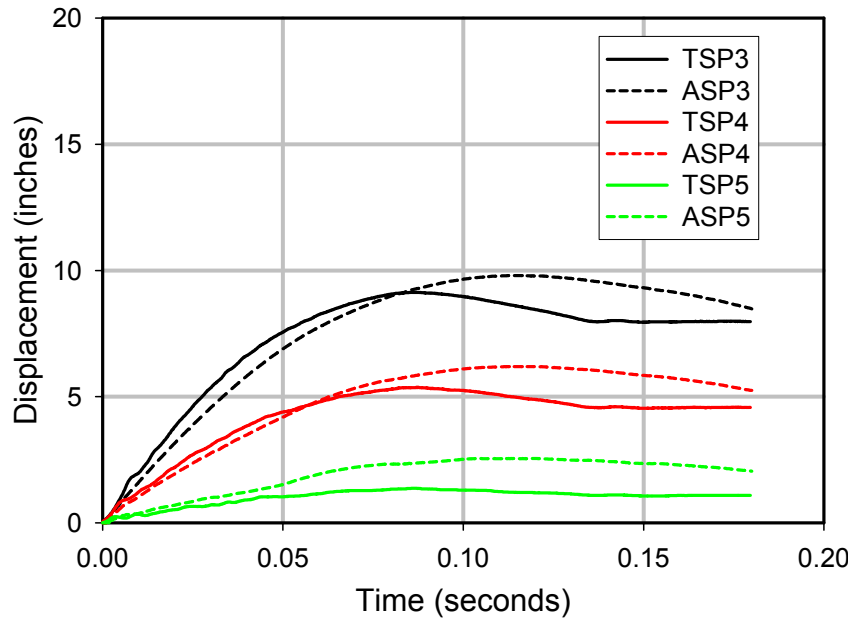

Figure 14 Measured and Predicted Longitudinal DisplacementTime Histories on SOA Corner Post

Figure 15 shows three still photographs taken from a high-speed movie film of the test of the SOA design. The first frame shows the coil and corner post at the instant of impact, the second frame shows the coil and the cab car after approximately 0.03 seconds and 5.25 inches rearward displacement of the corner post. The third frame shows the coil and the cab car after approximately 0.08 seconds and 9 inches of displacement of the corner post. Just below those three frames are results from the pre-test analysis with material failure for the mode shape of the cab car end structure at the same times and nearly the same displacements. The predicted mode shape closely matches the mode shape observed in the test. There is slightly more vertical distortion of the roof above the upper trailing corner near-side doorway predicted by the model than seen in the test result. Similar late changes in the attachment of the end frame to the original car structure were made in the SOA design as in the 1990's design, however, the SOA design is not as sensitive to these changes, since the corner post was attached to both the top and bottom plates of the antitelescoping plate. The additional strength of the attachment in the SOA design forced the anti-telescoping plate to deform downward, rather than allowing the attachment to fail, as it did in the 1990's design.

Despite the minor differences discussed between the pre-test and test measurements overall there is very good agreement in terms of total energy consumed through plastic deformations as well as modes of deformation and failure. This information is then provided as input into the collision dynamics models discussed in the companion paper. The next section discusses in greater detail the areas that experienced material failure for both sets of tests.

\section{Material Failure}

As shown in the force/crush characteristics in Figures 7 and 12, modeling of material failure was necessary for accurate prediction of the force/crush characteristic. Material failure occurred at multiple locations in both tests and under a range of stress-states. Material failure was sufficiently extensive in the test of the 1990's design to allow separation of the top of the corner post from its attachment to the anti-telescoping plate and separation of the lateral member/shelf from the corner post.

In both tests the corner post acted largely as a fixed-pinned beam that is overloaded. A plastic hinge formed early in the test near the center of impact. As the test progressed, the corner post bent into a 'V,' which put a significant tension load on the corner post. Both the upper and lower attachment of the corner post had to support the shear
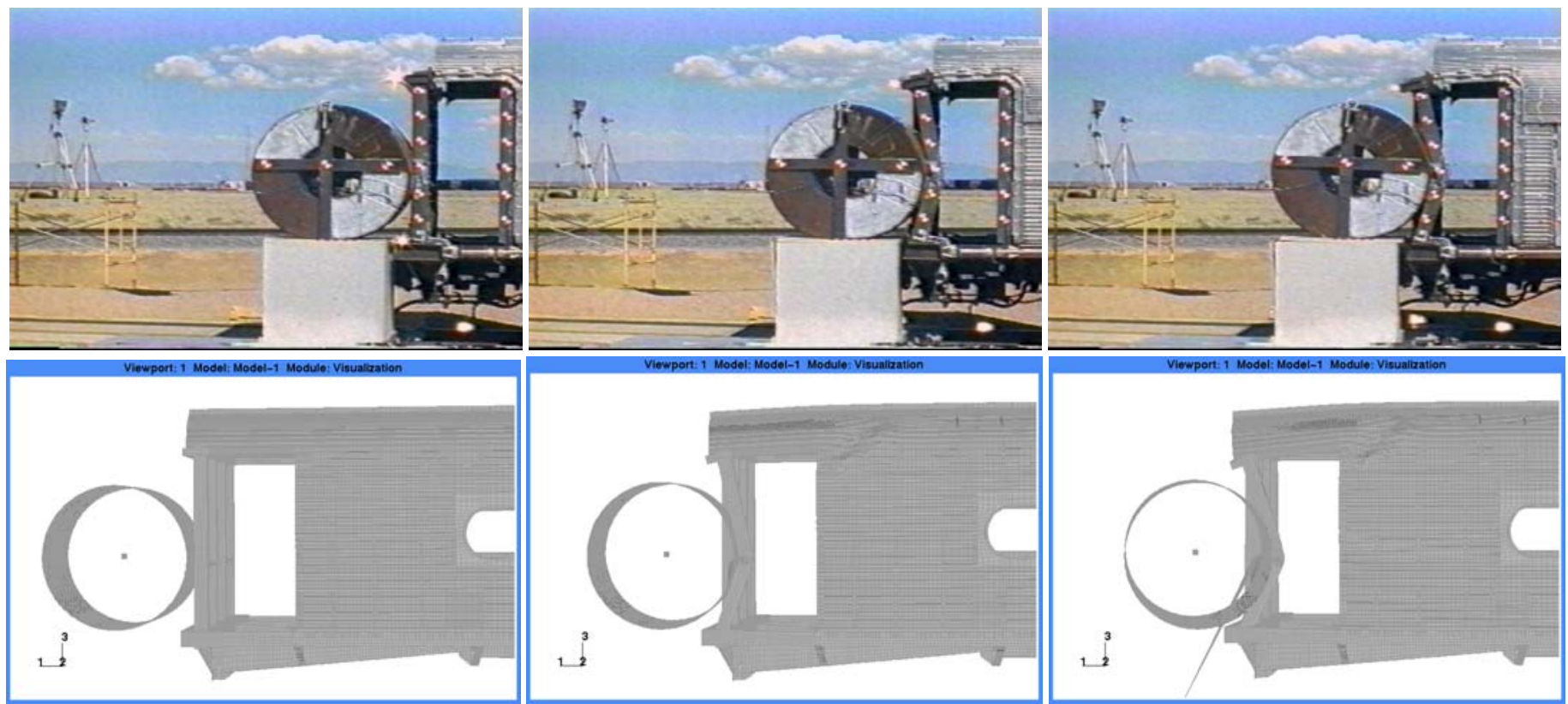

Figure 15. Measured and Pre-Test Predicted Mode of Deformation, SOA Design 
load from the coil and the tension load due to the bending of the beam. The end beam did not visibly plastically deform, and so the floor attachment acted as a fixed connection. The anti-telescoping plate and the cant rail did deform downward, and consequently the roof connection of the corner post acted as a pinned connection. A posttest photograph of the deformed shape of the corner post is shown in Figure 3.

Material failure occurred in the 1990's end frame design test at the attachment of the corner post to the end beam, at the attachment of the corner post to the anti-telescoping plate, and at the attachment of the lateral member/shelf to the corner post. Close-ups of the material failures at these locations are shown in Figure 16. The left hand photograph shows the failure that occurred at the base of the corner post/end beam connection. As the central hinge in the corner post rotated and pushed inwards large bending and tensile stresses developed on the top plate of the end beam on the impact side, while large bending and compressive stresses devolved on the aft side of the connection. The failure of the top plate is in the parent material of the sheet just outside the weld, effectively in the heat-affected zone. The photograph on the center shows the top of the corner post, which pulled out of the anti-telescoping-plate during the collision. The stress state to cause this failure mode was almost a pure state of shear. The right side photograph shows the attachment of the lateral member/shelf to the collision post. This connection failed due to the combination of bending and shear.

Material failure occurred in the SOA end frame design test at the connection of the corner post to the end beam, at the attachment of the anti-telescoping plate to the cant rail, and at the attachment of the lateral member/ shelf to the corner post. Figure 17 shows photographs of the material failure at these locations. Again as the central plastic hinge rotated and displaced inwards large tensile and bending stresses developed on the impacting side of the corner post at its connection with the end beam, while large bending and compressive stresses developed on the aft side of the corner post. Unlike the failure mode experienced by the 1990's end frame design, this time the parent material in the corner post rather than the end beam failed. The failure progressed nearly the full depth of the post. There is no upward bending in the end beam upper flange because this design had the corner post penetrating through both the upper and lower flanges of the end beam, and the end beam was reinforced by the closed side sill that extended all the way forward from the aft operators compartment wall. The necking/cup-cone deformations present on both the pulledout post and the in-situ post are indicative of a tensile failure that then proceeded to further open due to the combined tension and bending. The material failure that occurred at the anti-telescoping connection with the cant rail was in the region of a weld. This failure mode was caused by the rotation of the anti-telescoping plate as the central hinge displaced inwards and a prying load ensued between the antitelescoping pad connection point and the cant rail. Finally, the last area with material failure is at the connection point of the bulkhead sheet with the lateral member/shelf and the collision post. As the coil penetrated inwards during the collision, both the bulkhead sheet and the lateral member/shelf transmitted load to the collision post. Large tensile and shear stresses developed at this connection point. The failure proceeded from the outside inwards and downwards between the collision post and bulkhead sheet weld.

As described earlier, currently material failure is modeled in many finite-element analysis packages using a simple strain-to-failure criterion. When the total strain on an element reaches an input value, that element is removed from the mesh. This approach works well when the principal cause of material failure is tension and the extent of material failure is limited. Limitations of the current approach to modeling material failure include the fact that materials fail at different strains in tension, compression, and shear [14] and the fact that once material failure has initiated, lower strain is needed to propagate the failure [13].

Sophisticated application of current finite-element analysis packages allow these limitations to be overcome to some degree. By first running the model without material failure, the areas of high strain and potential material failure can be found. The model then can be run again with the parameters associated with material failure adjusted to account for the stress state of the high-strain areas. If the three-dimensional stress state of two or more high-strain areas substantially differ - for example, one in tension and one in compression - then the model can be sub-structured and different material-failure parameters applied to each substructure. An effort is currently underway to better understand material failure under a widerange of strain states and to develop algorithms that more accurately predict material failure [15].
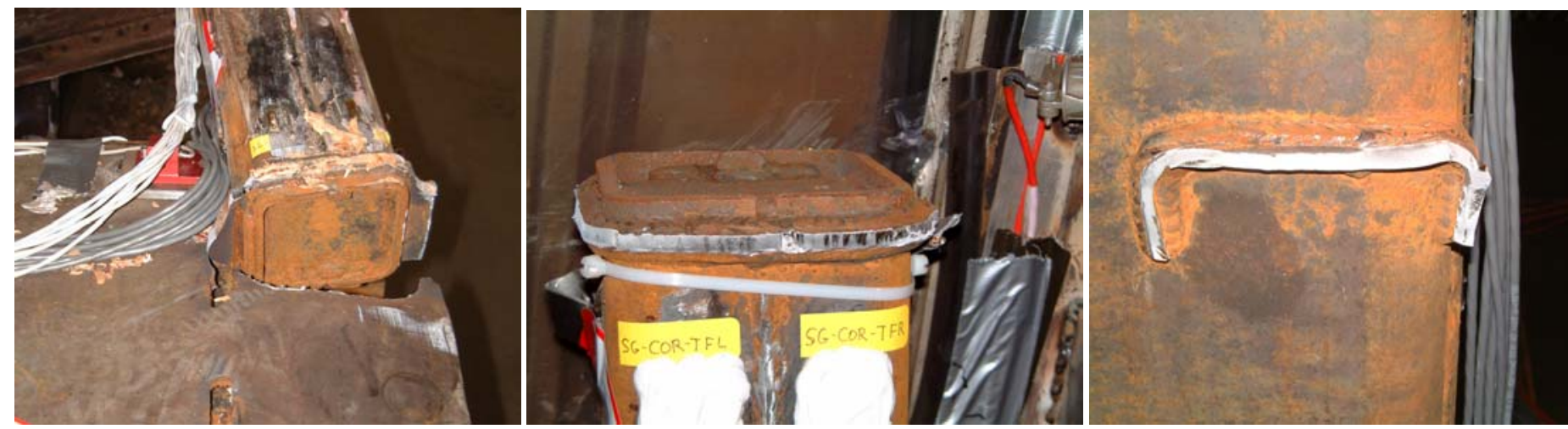

Figure 16. Post-Test Photographs of Material Failure in 1990's Design, Corner Post Connection to End Beam, Failed Connection at Top of Corner Post, and Failed Connection to Shelf on Collision Post 

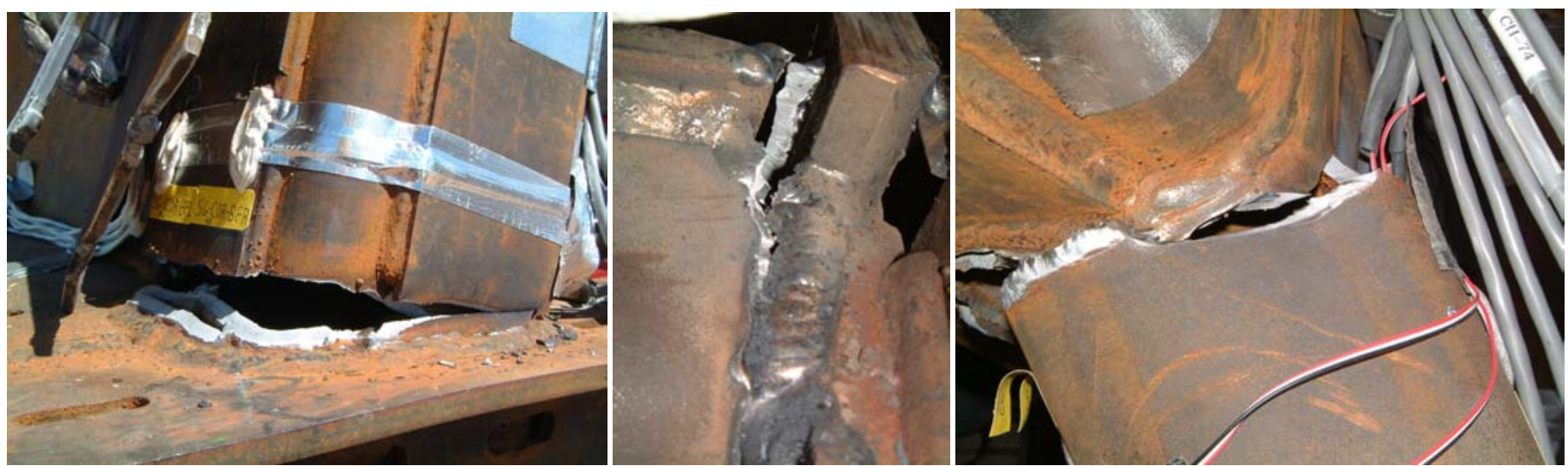

Figure 17. Post-Test Photographs of Material Failure in SOA Design, Corner Post Connection to End Beam, Anti-Telescoping Plate Connection to Roof Plate, and Shelf Connection to Collision Post

\section{SUMMARY AND DISCUSSION}

The grade-crossing collision tests were conducted to measure the effectiveness of alternative cab car end structures in preventing intrusion during a grade-crossing collision. The test conditions developed were based in part on the Portage, Indiana collision between a cab-car led commuter train and a tractor-tandem trailer carrying steel coils, and the Yardley, Pennsylvania collision between a cab car led commuter train with a semi-trailer carrying steel coils. The results of the test of the 1990's design show that this corner post is not sufficient to preserve the operator's volume in such an impact. During SOA test, the corner post remained attached and intrusion was kept below one foot of crush thus preserving occupied volume for the conductor to ride out the collision.

The pre-test analyses are close to the test measurements taken from the 1990's end frame design test. Revision of the model to include late changes in the design and to account for limitations in the approach to evaluating material failure in current finite element packages bring the model results into close agreement with the test predictions. The pre-test analysis predictions virtually overlay the test results for the force/crush characteristic for the SOA design. Both sets of analyses are capable of predicting the correct modes of deformation and the total amount of energy consumed during the collision well. Some work was required to obtain all failure modes observed. Careful application of finite-element modeling allowed accurate prediction of the crush behavior of rail car structures, in spite of limitations to the approach to modeling material failure in current finite-element analysis packages.

\section{APPENDIX - END FRAME DESIGN DETAILS}

The difference in the corner post designs is principally due to the different requirements for the corner posts in the 1990's design and in the SOA design. Prior to 1999, when the FRA issued its Passenger Equipment Safety Standards and APTA issued its Manual of Standards and Recommended Practices, there were no Federal Regulations or industry-wide standards for corner- post strength. Typical practice for corner post load requirements is illustrated in the left schematic of Figure 18. The current APTA cab car corner post requirements are illustrated in the right schematic of Figure 18. The current requirements double the shear loads at the floor and more than triple the load at 18 inches. In addition, a load above 18 inches in included. The APTA load requirements are greater than the FRA requirements, and are the principal driver for the differences in the two corner post designs.
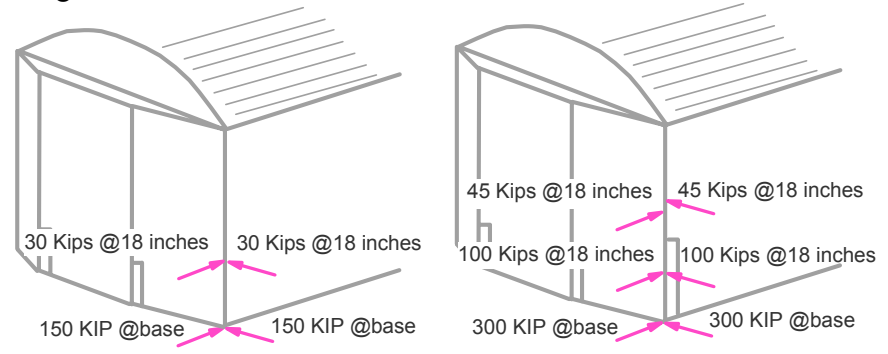

Note: Full Shear
Reinforcement to $30^{\circ}$

Figure 18. Corner Post Static Load Requirements, 1990 and SOA Designs

Figure 19 depicts schematics of the differences in both the corner post and collision post sections for the two end frame designs. In terms of cross-sections it is apparent how much larger the corner post is in the SOA design compared to the 1990's design. Even though there are differences in load requirements for the collision posts, the two designs have very similar cross-sections.

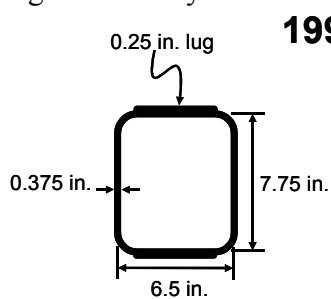

Collision Post 990's Design

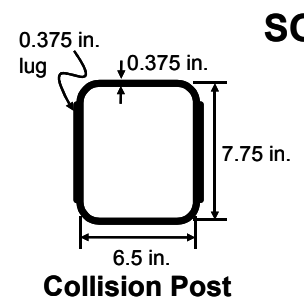

SOA Design

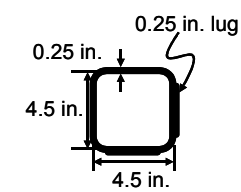

Corner Post

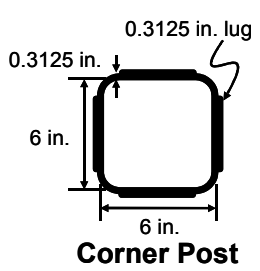

Figure 19. Schematics Contrasting 1990 and SOA End Frame Designs; Collision and Corner Posts as Tested 
An ASTM A 710 Grade A Class 3 steel was used to construct both end frame designs. This steel was chosen for it's higher yield and ultimate strengths as well as it's good ductility. An additional requirement placed the SOA design is that it must deform without failure for a crush distance at least as long as the post is deep. Failure is to occur in the post itself and not in the connection. This failure mode was exhibited in the SOA test while a connection failure occurred in the 1990's test.

The FRA regulation and APTA standards do not fully prescribe all the requirements that a functional cab car end structure must meet; that is, they are necessary but not sufficient to fully describe the design. There are many alternative designs that can potentially meet the regulations and standards, and each may be expected to behave somewhat differently under dynamic loading conditions. In addition to the static loads prescribed by the FRA regulations and APTA standards, the SOA design was also developed against requirements for post-yield behavior, i.e., the structure was designed to deform gracefully. The full set of design requirements, the static load tests performed to demonstrate compliance of the designs to the appropriate regulations and standards, and the details of the designs themselves are described in a draft report that is currently being reviewed for publication.

\section{ACKNOWLEDGEMENTS}

Dr. Barrie Brickle, Senior Engineer, Transportation Technology Center, Inc. (now retired) was the test engineer who implemented the grade-crossing tests. Kent Johnson, President, Premier Engineering, and Dr. Ron Mayville, Manager, Applied Mechanics Unit, Tiax, LLC designed the SOA and 1990's end frames. Dr. Richard Stringfellow, Senior Engineer and Patricia Llana, Mechanical Engineer, Tiax, LLC developed the finite element models of the SOA and 1990's end frames. Dr. Steven Kirkpatrick, ARA, Inc developed the Pioneer Car finite element model, into which the end frame models were incorporated. (The integrated end frame/Pioneer car model was modified by one of the authors, Eloy Martinez, to simulate the impact with the coil and to include material failure.) The authors along with Professor A. Benjamin Perlman, Tufts University, designed the gradecrossing tests.

The design of the tests was developed in coordination with the Construction/Structural Subcommittee of APTA's Passenger Rail Equipment Safety Standards Committee. The author's would like to thank Ken Barnish, Assistant Chief Mechanical Officer, Metro-North Railroad, Chair of the Subcommittee, and Tom Peacock, Manager, Technical Services, APTA for their efforts to coordinate the activities.

This work was performed as part of the Equipment Safety Research Program sponsored by the Office of Research and Development of the Federal Railroad Administration. The authors would like to thank Dr. Tom Tsai, Program Manager, and Claire Orth, Division Chief, Equipment and Operating Practices Research Division, Office of Research and Development, Federal Railroad Administration, for their support. The authors would also like to thank Gunars Spons, Federal Railroad Administration Resident Manager at the Transportation Technology Center, for managing the full-scale test effort.

\section{REFERENCES}

[1] American Public Transportation Association, Member Services Department, Manual of Standards and Recommended Practices for Passenger Rail Equipment, Issue of July 1, 1999.
[2] VanIngen-Dunn, C., Manning, J., "Commuter Rail Seat Testing and Analysis," US Department of Transportation, DOT/FRA/ORD01/06, July 2002.

[3] Final Report "Railroad Vehicle Glazing Impact Strength Testing Program" Prepared by Parsons Brinkenhoff Quade \& Douglas Inc. Boston, MA in asscociation with ETC Laboratories Rochester, NY, July 15,1999

[4] Tyrell, D., K. Severson, A.B. Perlman, "Single Passenger Rail Car Impact Test Volume I: Overview and Selected Results," U.S. Department of Transportation, DOT/FRA/ORD-00/02.1, March 2000.

[5] Tyrell, D., K. Severson, A.B. Perlman, "Passenger Rail Two-Car Impact Test Volume I: Overview and Selected Results," U.S. Department of Transportation, DOT/FRA/ORD-01/22.I, January 2002.

[6] Tyrell, D., Severson, K., Perlman, A.B., Rancatore, R., "Train-toTrain Impact Test: Analysis of Structural Measurements," American Society of Mechanical Engineers, Paper No. IMECE2002-33247, November 2002.

[7] National Transportation Safety Board, "Collision of Northern Indiana Commuter Transportation District Train 102 with a TractorTrailer Portage, Indiana June 18,1998”, 07/26/1999, RAR-99-03.

[8] National Transportation Safety Board, "Collision of Reading Company Commuter Train and Tractor-Semitrailer, Near Yardley Pennsylvania, June 5, 1975," RAR-76-4, 03/03/1976.

[9] Jacobsen, K., Tyrell, D., Perlman, A.B., Grade-Crossing Impact Tests: Collision Dynamics," to be presented at the Spring ASME/IEEE Joint Railroad Conference, April 2003.

[10] White, J.H., Jr., "The American Railroad Passenger Car," The Johns Hopkins University Press, 1978.

[11] ABAQUS/Explicit Users Manual, Version 5.8, 1998, Hibbitt, Karlsson and Sorenson, Inc.

[12] Martinez, E., and Tyrell, D., "Alternative Analyses of Locomotive Structural Designs for Crashworthiness," American Society of Mechanical Engineers, November 5-10, 2000, Orlando FL.

[13] Bao, Y., and Wierzbicki, T., "Comparative Study of Fracture Criteria: Part II - Finite Element Analysis," Impact and Crashworthiness Laboratory, Report No. 67, November 2001.

[14] Bao, Y. and Wierzbicki, T., "Determination of Fracture Locus for the 2024T351 Aluminum," Impact and Crashworthiness Laboratory, Report No. 81, May 2002.

[15] Volpe Center Contract DTRS57-98-D-00043, Task Order 9: Investigation of Failure Mechanisms in Railroad Equipment Structures, with Massachusetts Institute of Technology, issued October, 2002. 